\title{
PENGARUH BUDAYA ORGANISASI, KEPEMIMPINAN DAN MOTIVASI TERHADAP KOMITMEN ORGANISASI DAN KINERJA PEGAWAI POLITEKNIK ILMU PELAYARAN (PIP) SEMARANG
}

\author{
Romanda Annas Amrullah \\ Dosen Program Studi KALK PIP Semarang
}

\begin{abstract}
The Success and agency performance can be seen from the performance achieved by its employees, therefore, the agency demanded that the employee is able to display optimal performance. Increasing the performance of the employees needs to be done in order to be optimized to work out where the performance is determined by the organizational culture, leadership, motivation and organizational commitment. This study aims to determine how much influence organizational culture, leadership, motivation and organizational commitment on organizational commitment. To determine the influence of organizational commitment to employee performance.

Based on the results of data analysis can be concluded. There is a positive and significant influence of organizational culture on organizational commitment. There is a positive and significant impact of leadership on organizational commitment. There is a positive and significant effect of motivation on organizational commitment. There is a positive and significant influence of organizational culture, leadership and motivation together on organizational commitment. There is a positive and significant effect of organizational commitment to employee performance, coefficient of determination amounted to 0,645, which means a variation change organizational commitment influenced the culture of the organization, leadership and motivation of $64.5 \%$, while the rest $35.5 \%$ influenced by other factors outside the research.
\end{abstract}

\section{Keywords: Organizational Culture, Leadership Motivation, Organizational Commitment, Employee Performance}

\section{PENDAHULUAN}

Kinerja pada dasarnya adalah kegiatan dan hasil yang dapat dicapai atau dilanjutkan seseorang atau sekelompok orang didalam pelaksanaan tugas, pekerjaan dengan baik, artinya mencapai sasaran atau standar kerja yang telah ditetapkan sebelum atau bahkan dapat melebihi standar yang ditentukan oleh organisasi pada periode tertentu (Handoko, 2005).

Kinerja yang dimiliki oleh birokrasi pada hakikatnya merupakan suatu akibat dari persyaratan kerja yang harus dipenuhi oleh karyawan. Kinerja sangat ditentukan oleh karyawan yang berkualitas (Indriani dan Waluyo, 2012). Organisasi dalam mendapatkan karyawan yang berkualitas harus meninggalkan kebijakan praktek manajemen yang sifatnya hakiki dan fungsional, bergeser pada praktek-praktek baru di bidang manajemen yang lebih inovatif, dan adaptif dalam merespon lingkungan yang cepat berubah. Kinerja merupakan suatu hasil yang dicapai oleh karyawan dalam pekerjaannya menurut kriteria tertentu yang berlaku untuk suatu pekerjaan (Robbins, 2006). Menurut Hessel (2007) faktor faktor yang mempengaruhi kinerja karyawan adalah motivasi, budaya organisasi, kompensasi, kepemimpinan, kepuasan kerja, kedisiplinan, lingkungan kerja dan komitmen organisasi.

Berdasarkan latar belakang masalah, maka rumusan masalah adalah "Bagaimana meningkatkan kinerja pegawai Politeknik Ilmu Pelayaran (PIP) Semarang" kemudian muncul pertanyaan penelitian sebagai berikut: 1) Seberapa besar pengaruh budaya organisasi terhadap komitmen organisasi? 2) Seberapa besar pengaruh kepemimpinan terhadap komitmen organisasi? 3) Seberapa besar pengaruh motivasi terhadap komitmen organisasi? 4) Seberapa besar pengaruh budaya organisasi, kepemimpinan dan 
motivasi secara bersama-sama berpengaruh terhadap komitmen organisasi? 5) Seberapa besar pengaruh komitmen organisasi terhadap kinerja pegawai?

Menurut Robbins (2006), budaya organisasi adalah suatu persepsi bersama yang dianut oleh anggota-anggota organisasi itu. Stoner et al (2002) menyatakan budaya (culture) merupakan gabungan kompleks dari asumsi, tingkah laku, cerita, mitos, metafora dan berbagai ide lain yang menjadi satu untuk menentukan apa arti menjadi anggota masyarakat tertentu.

Budaya organisasi menurut Gibson (2006) adalah seperangkat asumsi, keyakinan, nilai-nilai dan norma-norma di antara para anggota organisasi. Budaya organisasi merupakan faktor yang kuat untuk menentukan perilakku individu dan perilaku kelompok di dalam suatu organisasi.

Karakteristik budaya organisasi, menurut Robbins (2006) adalah 1) Inovasi dan mengambil resiko. 2) Perhatian yang detail. 3) Orientasi hasil. 4) Orientasi manusia dan 5) Agresivitas.

Menurut Robbins (2006) menyatakan bahwa kepemimpinan sebagai kemampuan untuk memengaruhi suatu kelompok guna mencapai sebuah visi atau serangkaian tujuan yang ditetapkan. Menurut Wahjusumidjo (2003) kepemimpinan adalah sebagai bentuk hubungan sekelompok orang, hubungan antara yang memimpin dan yang dipimpin.

Untuk mengintergasikan tujuan organisasi dengan tujuan individu untuk mencapai tujuan tertentu, setiap pemimpin mempunyai sifat-sifat sebagai berikut : (Heidjrachman dan Husnan, 2008) : 1) Keinginan untuk menerima tanggung jawab. 2) Kemampuan untuk bisa "Perceptive". 3) Kemampuan untuk bersikap obyektif. 4). Kemampuan untuk menentukan prioritas dan. 5) Kemampuan untuk berkomunikasi

Motivasi juga diartikan sebagai kehendak atau dorongan untuk melakukan sesuatu dalam memenuhi kebutuhan atau bisa diartikan sebagai proses yang menyebabkan tingkah laku seseorang menjadi bergairah, terarah dan tidak mudah putus asa (Mulyadi, 2008). Mas'ud (2004) mendefinisikan motivasi sebagai pendorong (penggerak) yang ada dalam diri seseorang untuk bertindak.

Sedangkan faktor-faktor yang mempengaruhi motivasi yang dikemukakan oleh Maslow yang dikutip oleh As'ad, (2004), kebutuhan-kebutuhan manusia dapat digolongkan dalam lima tingkatan yaitu : 1) Kebutuhan fisologis (Physiological Needs). 2) Kebutuhan rasa aman (safety Needs). 3) Kebutuhan-kebutuhan sosial (Social Needs). 4) Kebutuhan akan harga diri (Esteem Needs). 5) Kebutuhan aktualisasi diri (Self Aktualization)

Mowday et. al. (1982 dalam Devi, 2009) mendefinisikan komitmen organisasional sebagai kekuatan relatif dari identifikasi individu dan keterlibatan dalam organisasi khusus, meliputi kepercayaan, dukungan terhadap tujuan dan nilai-nilai organisasi, dan keinginan yang kuat untuk menggunakan upaya yang sungguh sungguh untuk kepentingan organisasi, dan kemauan yang kuat untuk memelihara keanggotaan dalam organisasi.

Allen dan Meyer (1993 dalam Devi, 2009) mengajukan tiga model komitmen organisasional dan direfleksikan dalam tiga pokok utama yaitu: Affective commitment, Continuance commitment dan Normative commitment.

Kinerja merupakan hasil pekerjaan yang sesuai dengan tujuan organisasi, yakni kualitas kerja, kuantitas kerja, efisiensi, dan kriteria efektivitas lainnya (Gibson et al, dalam Riani, 2011). Sedangkan menurut Rivai dan Basri (2005) kinerja adalah kesediaan seseorang atau kelompok orang untuk melakukan sesuatu kegiatan dan menyempurnakannya sesuai dengan tanggungjawab dengan hasil seperti yang diharapkan.

Menurut Hakim (2006) mendefinisikan kinerja sebagai hasil kerja yang dicapai oleh individu yang disesuaikan dengan peran atau tugas individu tersebut dalam suatu perusahaan pada suatu periode waktu tertentu, yang dihubungkan dengan suatu ukuran nilai atau standar tertentu dari perusahaan dimana individu tersebut bekerja.

Menurut Noe et.al. (dalam As'ad, 2004) mengatakan ada enam kriteria yang 
Romanda Annas Amrullah

digunakan untuk mengukur sejauh mana kinerja karyawan secara individu yaitu Kualitas, Kuantitas, Ketepatan waktu,
Efektivitas, Kemandirian dan Perasaan mampu melakukan pekerjaan.

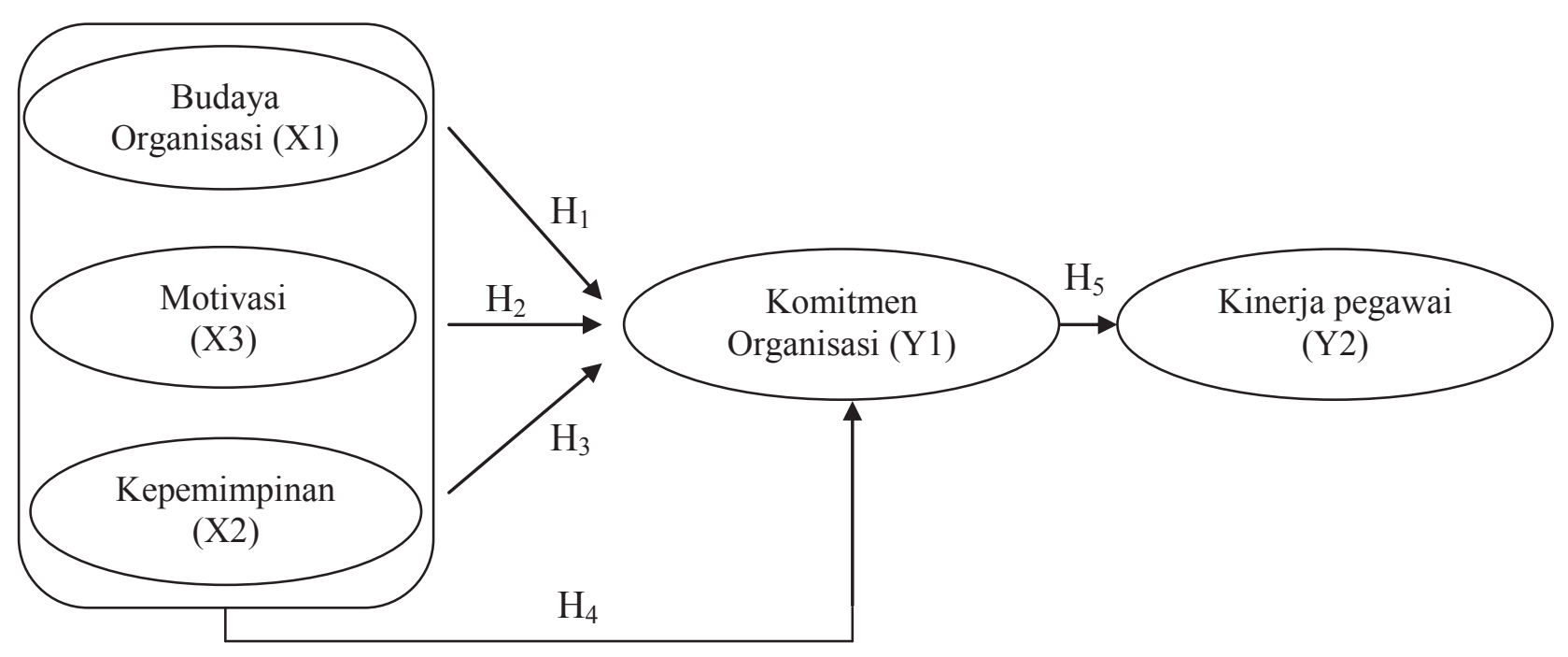

Gambar 1

Kerangka Pemikiran Teoritis

\section{Hipotesis}

$\mathrm{H}_{1}=$ Diduga terdapat pengaruh positif dan signifikan antara budaya organisasi terhadap komitmen organisasi Politeknik Ilmu Pelayaran (PIP) Semarang

$\mathrm{H}_{2}=$ Diduga terdapat pengaruh positif dan signifikan antara kepemimpinan terhadap komitmen organisasi Politeknik Ilmu Pelayaran (PIP) Semarang

$\mathrm{H}_{3}=$ Diduga terdapat pengaruh positif dan signifikan antara motivasi terhadap komitmen organisasi Politeknik Ilmu Pelayaran (PIP) Semarang

$\mathrm{H}_{4}=$ Diduga terdapat pengaruh positif dan signifikan antara budaya organisasi, kepemimpinan dan motivasi secara bersama-sama terhadap komitmen organisasi Politeknik Ilmu Pelayaran (PIP) Semarang

$\mathrm{H}_{5}=$ Diduga terdapat pengaruh positif dan signifikan antara komitmen organisasi terhadap kinerja pegawai Politeknik Ilmu Pelayaran (PIP) Semarang

\section{HASIL DAN DISKUSI}

\section{Analisis Regresi Berganda}

Tabel 1

Ringkasan Hasil Perhitungan Regresi Linier Berganda

Coefficients $^{\mathrm{a}}$

\begin{tabular}{|c|c|c|c|c|c|c|}
\hline & \multirow[t]{2}{*}{ Model } & \multicolumn{3}{|c|}{$\begin{array}{lc} & \begin{array}{c}\text { Standar } \\
\text { dized }\end{array} \\
\text { Unstandardize } & \text { Coef- } \\
\text { d Coefficients } & \text { ficients } \\
\end{array}$} & \multirow[t]{2}{*}{$\mathrm{t}$} & \multirow[t]{2}{*}{ Sig. } \\
\hline & & B & $\begin{array}{l}\text { Std. } \\
\text { Error }\end{array}$ & Beta & & \\
\hline \multirow{4}{*}{. } & (Constant) & 3.748 & 1.470 & & 2.549 & .013 \\
\hline & $\begin{array}{l}\text { Budaya } \\
\text { organisasi }\end{array}$ & .274 & .085 & .351 & 3.219 & .002 \\
\hline & $\begin{array}{l}\text { Kepemimp } \\
\text { inan }\end{array}$ & .299 & .087 & .334 & 3.450 & .001 \\
\hline & Motivasi & .223 & .097 & .236 & 2.290 & .025 \\
\hline
\end{tabular}

a. Dependent Variable: Komitmen organisasi

Berdasarkan tabel 1 dapat dijelaskan analisis sebagai berikut:

$$
\begin{aligned}
\mathrm{Y}_{1}= & 3,748+0,274 \mathrm{X}_{1}+0,299 \mathrm{X}_{2}+ \\
& 0,223 \mathrm{X} 3
\end{aligned}
$$

Dari hasil regresi tersebut dapat disimpulkan bahwa budaya organisasi (X1), 
kepemimpinan (X2) dan motivasi $\left(\mathrm{X}_{3}\right)$ berpengaruh positif terhadap komitmen organisasi $\left(\mathrm{Y}_{1}\right)$.

\section{Regresi Linier Sederhana}

Tabel 2

Ringkasan Hasil Perhitungan Regresi Linier Sederhana

\begin{tabular}{|c|c|c|c|c|c|}
\hline \multicolumn{6}{|c|}{ Coefficients $^{\mathrm{a}}$} \\
\hline \multirow[t]{2}{*}{ Model } & $\begin{array}{r}\text { Unsta } \\
\text { diz } \\
\text { Coeffi }\end{array}$ & $\begin{array}{l}\text { ndar- } \\
\text { zed } \\
\text { icients }\end{array}$ & $\begin{array}{c}\text { Standar } \\
\text { dized } \\
\text { Coef- } \\
\text { ficients }\end{array}$ & $\mathrm{t}$ & Sig. \\
\hline & B & $\begin{array}{l}\text { Std. } \\
\text { Error }\end{array}$ & Beta & & \\
\hline (Constant) & 2.708 & 2.135 & & 1.269 & .209 \\
\hline $\begin{array}{l}1 \text { Komitmen } \\
\text { organisasi }\end{array}$ & 1.022 & .102 & .763 & 10.013 & .000 \\
\hline
\end{tabular}

a. Dependent Variable: Kinerja Pegawai

Berdasarkan tabel 2 dapat dijelaskan analisis sebagai berikut:

$\mathrm{Y}_{2}=2,708+1,022 \mathrm{Y}_{1}$

Dari hasil regresi tersebut dapat disimpulkan bahwa komitmen organisasi $\left(\mathrm{Y}_{1}\right)$ berpengaruh positif terhadap kinerja pegawai $\left(\mathrm{Y}_{2}\right)$

\section{Pengujian Hipotesis}

a. Uji t

1) Pengujian Hipotesis Budaya Organisasi Terhadap Komitmen Organisasi

Dari hasil perhitungan t-hitung $(3,219)>t$-tabel $(1,666)$ atau sig $t$ $0,002<0,05$, dengan demikian H1 diterima. Maka dapat disimpulkan ada pengaruh positif dan signifikan budaya organisasi terhadap komitmen organisasi. Hasil penelitian ini sejalan dengan penelitian Indriyani (2011). Hal ini berarti budaya organisasi merupakan hal yang sangat penting dan berkaitan dengan komitmen organisasi. Hal ini dapat dijelaskan karena objek yang diteliti adalah pegawai negeri sipil yang dalam melaksanakan pekerjaannya telah memiliki aturan dan petunjuk yang jelas tentang tugas pokok dan tanggung jawabnya. Dengan kata lain, dapat dinyatakan bahwa budaya organisasi sebagai faktor utama dalam meningkatkan komitmen organisasi di Politeknik

Ilmu Pelayaran (PIP) Semarang. Hal ini menunjukkan bahwa semakin kuat budaya organisasi pada Politeknik Ilmu Pelayaran (PIP) Semarang, maka semakin tinggi komitmen organisasional dalam diri pegawai.

2) Pengujian Hipotesis Kepemimpinan Terhadap Komitmen Organisasi

Dari hasil perhitungan t-hitung $(3,450)>$ t-tabel $(1,666)$ atau sig $t$ $0,001<0,05$, dengan demikian $\mathrm{H} 2$ diterima. Maka dapat disimpulkan ada pengaruh positif dan signifikan kepemimpinan terhadap komitmen organisasi Politeknik Ilmu Pelayaran (PIP) Semarang. Hasil penelitian ini sejalan dengan penelitian Indriyani (2011). Hal ini mengindikasikan bahwa kepemimpinan merupakan faktor yang mempengaruhi komitmen organisasi. Hal ini berarti peran pemimpin dalam organisasi sangat penting karena menjadi ujung tombak bagi aktivitas pencapaian tujuan. Pemimpin tidak hanya mempengaruhi individu tetapi harus memiliki visi yang kuat sehingga organisasi bisa berjalan dan langgeng. Keberhasilan tersebut sangat ditentukan oleh gaya yang diterapkan dalam melaksanakan pengembangan organisasi. Pemimpin tidak bisa terpaku pada satu gaya tetapi bisa menggunakan beragam gaya sesuai dengan situasi yang berkembang dalam organisasi dan lingkungan. Semakin tepat gaya kepemimpinan yang diterapkan oleh pemimpin, semakin tinggi dampaknya bagi peningkatan komitmen organisasi pada pegawai.

3) Pengujian Hipotesis Motivasi Terhadap Komitmen Organisasi 
Dari hasil perhitungan t-hitung $(2,290)>$ t-tabel $(1,666)$ atau sig $\mathrm{t}$ $(0,025)<0,05$, dengan demikian $\mathrm{H} 3$ diterima. Maka dapat disimpulkan ada pengaruh positif dan signifikan motivasi terhadap komitmen organisasi. Hasil penelitian ini sejalan dengan penelitian Devi (2009), Indriyani (2011). Hal ini berarti Motivasi merupakan salah satu faktor penunjang dalam mencapai komitmen organisasi. Hal ini berarti dengan adanya motivasi yang tinggi akan meningkatkan komitmen organisasi. Dengan adanya motivasi yang tinggi berarti pula karyawan tersebut mempunyai minat yang tinggi dalam menjalankan rutinitas kerja sesuai dengan apa yang menjadi tanggung jawabnya. Dengan adanya minat yang tinggi, karyawan akan bekerja dengan perasaan senang. Motivasi yang tinggi ditunjukkan dari sikap positif pegawai terhadap pekerjaan. Sikap positif lainnya adalah merasa memiliki instansi dan mempunyai frekuensi kehadiran yang tinggi.

4) Pengujian Hipotesis Komitmen Organisasi Terhadap Kinerja Pegawai

Dari hasil perhitungan t-hitung $(10,013)>\mathrm{t}$-tabel $(1,666)$ atau sig $\mathrm{t}$ $(0,000)<0,05$, dengan demikian H5 diterima. Maka dapat disimpulkan ada pengaruh positif dan signifikan komitmen organisasi terhadap kinerja pegawai Politeknik Ilmu Pelayaran (PIP) Semarang. Hasil penelitian ini sejalan dengan penelitian Suwardi dan Utomo (2011). Komitmen organisasi sebagai sikap yang menunjukkan "loyalitas" pegawai dan merupakan proses berkelanjutan bagaimana seorang anggota organisasi mengekspresikan perhatian mereka kepada kesuksesan dan kebaikan organisasinya. Komitmen maknanya sama dengan menjalankan kewajiban, bertanggungjawab, dan janji yang membatasi seseorang untuk melakukan sesuatu. Pegawai dengan komitmen yang tinggi dapat diharapkan mampu menunjukkan kinerja yang optimal. Seorang pegawai akan bekerja secara maksimal, memanfaatkan kemampuan dan ketrampilannya dengan bersemangat, manakala ia memiliki komitmen organisasi yang tinggi. Dalam menjalankan suatu instansi atau instansi merupakan pekerjaan kelompok (team) dan bukan merupakan pekerjaan yang dikerjakan secara individu, maka dibutuhkan adanya komitmen organisasi yang dapat menimbulkan perilaku yang positif bagi pegawai. Pegawai dengan komitmen tinggi biasanya lebih tahan bekerja, produktif dan berorientasi kearah pencapaian tujuan organisasi, sehingga kinerja menjadi optimal.

\section{b. Uji F}

Hasil perhitungan F-hitung $(45,296)>$ F-tabel $(2,736)$ atau sig $\mathrm{F}(0,000)<$ 0,05 , dengan demikian H4 diterima. Maka dapat disimpulkan ada pengaruh positif dan signifikan budaya organisasi, kepemimpinan dan motivasi secara bersama-sama terhadap komitmen organisasi Politeknik Ilmu Pelayaran (PIP) Semarang, hal ini dikarenakan komitmen organisasi Politeknik Ilmu Pelayaran (PIP) Semarang yang meningkat dapat dicapai apabila semakin baik budaya organisasi, kepemimpinan dan motivasi.

\section{Koefisien Determinasi}

Nilai koefisien determinasi adalah sebesar 0,645 yang berarti variasi perubahan komitmen organisasi Politeknik Ilmu Pelayaran (PIP) Semarang dipengaruhi budaya organisasi, kepemimpinan dan motivasi sebesar $64,5 \%$, sedangkan sisanya $35,5 \%$ dipengaruhi oleh faktor lain di luar penelitian (misalnya lingkungan kerja dan kemampuan kerja). 


\section{KESIMPULAN}

1. Terdapat pengaruh positif dan signifikan budaya organisasi terhadap komitmen organisasi Politeknik Ilmu Pelayaran (PIP) Semarang, hal ini dibuktikan dalam analisis statistik dimana nilai nilai koefisien regresi motivasi $\left(b_{1}\right)$ sebesar 0,274 dan $\mathrm{t}$ hitung $(3,219)>\mathrm{t}$ tabel $(1,666)$ atau sig t $0,002<0,05$, dengan demikian $\mathrm{H} 1$ diterima.

2. Terdapat pengaruh positif dan signifikan kepemimpinan terhadap komitmen organisasi Politeknik Ilmu Pelayaran (PIP) Semarang, hal ini dibuktikan dalam analisis statistik dimana nilai nilai koefisien regresi kepemimpinan $\left(b_{2}\right)$ sebesar 0,299 dan $\mathrm{t}$ hitung $(3,450)>\mathrm{t}$ tabel $(1,666)$ atau sig $t(0,001)<0,05$, dengan demikian $\mathrm{H} 2$ diterima.

3. Terdapat pengaruh positif dan signifikan motivasi terhadap komitmen organisasi Politeknik Ilmu Pelayaran (PIP) Semarang, hal ini dibuktikan dalam analisis statistik dimana nilai Nilai koefisien regresi motivasi $\left(b_{3}\right)$ sebesar 0,223 dan $\mathrm{t}$ hitung $(2,290)>\mathrm{t}$ tabel $(1,666)$ atau sig $\mathrm{t}(0,025)<0,05$, dengan demikian $\mathrm{H} 3$ diterima.

4. Terdapat pengaruh positif dan signifikan budaya organisasi, kepemimpinan dan motivasi secara bersama-sama terhadap komitmen organisasi Politeknik Ilmu Pelayaran (PIP) Semarang, hal ini dibuktikan dalam analisis statistik dimana $F$ hitung $(45,296)>F$ tabel $(2,736)$ atau $\operatorname{sig} \mathrm{F}(0,000)<0,05$, dengan demikian $\mathrm{H} 4$ diterima.

5. Terdapat pengaruh positif dan signifikan komitmen organisasi terhadap kinerja pegawai Politeknik Ilmu Pelayaran (PIP) Semarang, hal ini dibuktikan dalam analisis statistik dimana nilai Nilai koefisien regresi komitmen organisasi $\left(b_{1}\right)$ sebesar 1,022 dan $\mathrm{t}$ hitung $(2,290)>\mathrm{t}$ tabel $(1,666)$ atau sig $t(0,000)<0,05$, dengan demikian $\mathrm{H} 5$ diterima.

6. Nilai koefisien determinasi adalah sebesar 0,645 yang berarti variasi perubahan komitmen organisasi Politeknik Ilmu Pelayaran (PIP) Semarang dipengaruhi budaya organisasi, kepemimpinan dan motivasi sebesar $64,5 \%$, sedangkan sisanya $35,5 \%$ dipengaruhi oleh faktor lain di luar penelitian (misalnya lingkungan kerja dan kemampuan kerja).

\section{DAFTAR PUSTAKA}

Anoraga, Panji dan Ninik Widiyanti. 2003. Psikologi Dalam Perusahaan. Jakarta: Rineka Cipta

Arifin, H. Muhammad. 2015. The Influence of Competence, Motivation, and Organisational Culture to High School Teacher Job Satisfaction and Performance, International Education Studies; Vol. 8, No. 1; 2015

As'ad, Moh. 2004. Psikologi Industri. Yogyakarta: Liberty

Devi, Eva Kris Diana. 2009. Analisis Pengaruh Kepuasan Kerja dan Motivasi Terhadap Kinerja Karyawan Dengan Komitmen organisasional Sebagai Variabel Intervening (Studi Pada Karyawan Outsourcing PT Semeru Karya Buana Semarang), Tesis, Program Magister Manajemen (S-2). Semarang: Universitas Diponegoro

Ghozali, Imam. 2009. Aplikasi Analisis Multivariate. Semarang: Undip

Gibson, James L., Ivancevich, John M., Donnelly Jr, James H. 2006. Organisasi: Perilaku, Struktur, dan Proses. Jakarta: Penerbit Erlangga

Guritno, Bambang dan Waridin. 2005. Pengaruh Persepsi Karyawan Mengenai Perilaku Kepemimpinan, Kepuasan Kerja Dan Motivasi Terhadap Kinerja. JRBI. Vol 1. No 1. Hal: 63-74

Hakim, Abdul. 2006. Analisis Pengaruh Motivasi, Komitmen Organisasi Dan Iklim Organisasi Terhadap Kinerja Pegawai Pada Dinas Perhubungan Dan Telekomunikasi Provinsi Jawa Tengah. JRBI. Vol 2. No 2. Hal: 165-180 
Romanda Annas Amrullah

Handoko, T. Hani. 2005. Manajemen dan Sumber Daya Manusia. Yogyakarta: Liberty

Heidjrachman R. dan Husnan Suad. 2008. Manajemen Personalia. Yogyakarta: BPFE

Indriyani, Etty dan Wisnu Haryanto Petrus Christologus. 2011. Pengaruh Budaya Organisasi dan Kepuasan Kerja Terhadap Kinerja Karyawan Dengan Komitmen Organisasi Sebagai Variabel Intervening Pada Workshop SMK Katolik Santo Mikael Surakarta, Jurnal STIE-AUB, Surakarta

Indriyani, Etty dan Hari Waluyo. 2012. Pengaruh Kepemimpinan Dan Budaya Organisasi Terhadap Kinerja Pegawai Negeri Sipil di Sekretariat Daerah Kabupaten Karanganyar Dengan Komitmen Organisasi Sebagai Variabel Intervening, Jurnal STIE-AUB, Surakarta.

Kartono, Kartini. 2006. Pemimpin dan Kepemimpinan. Jakarta: Penerbit PT. Rajagrafindo Persada

Luthans, Fred. 2006. Organization Behavior. Englewood Cliff, New Jersey: Prentice-Hall, Inc

Nitasari, Rizka Afrisalia. 2012. Analisis Pengaruh Motivasi Kerja Terhadap Kinerja Karyawan dengan Kepuasan Kerja Sebagai Variabel Intervening Pada PT. Bank Central Asia Tbk. Cabang Kudus. Skripsi. Fakultas Ekonomika dan Bisnis Jurusan Manajemen Universitas Diponegoro, Semarang.
Nugroho, Dwiyekti Agung. 2011. Pengaruh Budaya Organisasi Dan Gaya Kepemimpinan Transformasional Terhadap Komitmen Organisasi Dan Kinerja Pegawai (Studi Pada Pusat Pengembangan danPemberdayaan Pendidik dan Tenaga Kependidikan/ Vocational Education Development CenterMalang), Jurnal Manajemen Bisnis, Volume 1 No.2 Edisi Oktober 2011

Purnami, Erni Sri dan Purwadi, Didik. 2011. Faktor-Faktor Yang Mempengaruhi Kinerja Pegawai Dalam Organisasi, DAYA SAING Jurnal Ekonomi Manajemen Sumber Daya Vol. 12, No. 1, Juni 2011

Riani, Asri Laksmi. 2011. Budaya Organisasi. Yogyakarta: Graha Ilmu

Rivai, Veithzal. 2004. Manajemen Sumber Daya Manusia Untuk Perusahaan. Jakarta: PT Rajagrafindo Persada

Rivai, Veithzal dan Basri. 2005. Performance Appraisal: Sistem Yang Tepat Untuk Menilai Kinerja Karyawan Dan Meningkatkan Daya Saing Perusahaan. Jakarta: PT Rajagrafindo Persada

Robbins, Stephen P. 2006. Perilaku Organisasi. Jakarta: Prehallindo

Schein, Edgar H. 2002. Organizational Culture \& Leadership. MIT Sloan Management Review, (http://www.tnellen.com/ted/tc/schein.html)

Soewarno H. 2006. Pengantar Studi Ilmu Administrasi dan Manajemen. Jakarta: Penerbit PT. Toko Gunung Agung 
Steer. 2008. Efektifitas Organisasi. Jakarta: Erlangga

Stoner, James A. F. 2002. Manajemen. Jakarta: Erlangga

Sugiyono. 2009. Statistika Untuk Penelitian. Bandung: Alfabeta

Suwardi dan Joko Utomo. 2011. Pengaruh Motivasi Kerja, Kepuasan Kerja Dan Komitmen Organisasional Terhadap Kinerja Pegawai (Studi Pada Pegawai Setda Kabupaten Pati), Analisis Manajemen Vol. 5 No. 1 Juli 2011

Umar, Husein. 2002. Metodologi Penelitian, Aplikasi Dalam Pemasaran. Jakarta: PT. Gramedia Pustaka Utama

Wahjusumidjo. 2003. Kepemimpinan dan Motivasi. Ghalia Indonesia

Waspodo, Tri dan Sutarno. 2009. Pengaruh Bimbingan, Kedisipilnan, Budaya Organisasi dan Kepemimpinan Terhadap Kinerja Pegawai Pada Kantor Departemen Agama, Jurnal Manajemen Sumberdaya Manusia Vol. 3 No. 140 Juni 2009.

Wirawan. 2007. Budaya dan Iklim Organisasi. Jakarta: Salemba Empat 